\title{
The usage of Games-Based Intervention in Improving the English Language Proficiency of High School B40 Students
}

\author{
Siti Salwa Isa ${ }^{1}$, Nor Lelawati Jamaludin ${ }^{2}$, Abu Ali ${ }^{1}$, Shahrul Niza Said ${ }^{3}$ \\ 1 Department of Industrial Design, Faculty of Art and Design, Universiti Teknologi MARA, 40450 Shah Alam Selangor, Malaysia \\ ${ }^{2}$ Department of International Business and Management Studies, Faculty of Business and Management, Universiti Teknologi MARA, \\ 42300, Puncak Alam Selangor, Malaysia, ${ }^{3}$ School of Languages, Civilisation and Philosophy, Universiti Utara Malaysia 06010 UUM \\ Sintok Kedah
}

sitisalwa@uitm.edu.my, abuali@uitm.edu.my,norlelawati0019@uitm.edu.my,nyza@uum.edu.my

Tel: +60138017304

\begin{abstract}
The objective of this study is explore the use game-based intervention as a tool in understanding its contributions to the level of English Language proficiency among B40 secondary school students in Klang Valley $(n=104)$. Results was tested using correlational study in SPSS. The level of English proficiency improvement of students was measured according to The Common European Framework of Reference for Languages (CEFR). Results indicate that more than $50 \%$ (54) shows a significant result in improvement with moderate-string correlation and statistically significant. This allows the curation of appropriate strategies and responses to address application development in English language learning if necessary.
\end{abstract}

Keywords: Game-based Intervention (GBI); UN Sustainable Development Goals 4 (SDG); The Common European Framework of Reference for Languages (CEFR); B40

eISSN: 2398-4287 (C) 2021. The Authors. Published for AMER ABRA cE-Bs by e-International Publishing House, Ltd., UK. This is an open access article under the CC BYNC-ND license (http://creativecommons.org/licenses/by-nc-nd/4.0/). Peer-review under responsibility of AMER (Association of Malaysian Environment-Behaviour Researchers), ABRA (Association of Behavioural Researchers on Asians) and cE-Bs (Centre for Environment-Behaviour Studies), Faculty of Architecture, Planning \& Surveying, Universiti Teknologi MARA, Malaysia.

DOI: https://doi.org/10.21834/ebpj.v6iSI6.3036

\subsection{Introduction}

The United Nations 2030 Agenda for Sustainable Development, or Sustainable Development Goals (SDGs), Education 2030Framework (UN, 2019) for action offers the development of more robust comprehensive assessment systems to assess learning outcomes at critical points, including assessment of foundational reading, writing, and numeracy skills as well as non-cognitive skills and designing formative assessments as an integral part at the teaching and learning process. This notion meets Malaysian education vision to adopt new methods of teaching and learning in line with the needs of today's technologically advanced generation of students, to better prepare students for any form of assessment. For generations, the issue of student's achievement in language literacy among secondary school students has not been unfolded. Various efforts have been put on improving language literacy skills, especially among students, through different approaches and tools. As to spark the interest and motivation in improving language literacy achievement among children, serious gamebased assessment is proposed to accommodate students with technological kits in a pragmatic learning approach.

Researchers in education have made significant advancements over the last two decades in theorizing, designing, and repurposing digital games for learning in and out of school (Plass, Mayer, \& Homer, 2020). In this research, the focus was on game-based intervention (GBI) using one selected application as a pedagogical tool that involves the testing of English language proficiency among students from the B40 economic status groups using existing games. This study concentrated on a nascent area of research in the field; that is, examining

eISSN: 2398-4287 @ 2021. The Authors. Published for AMER ABRA cE-Bs by e-International Publishing House, Ltd., UK. This is an open access article under the CC BYNC-ND license (http://creativecommons.org/licenses/by-nc-nd/4.0/). Peer-review under responsibility of AMER (Association of Malaysian Environment-Behaviour Researchers), ABRA (Association of Behavioural Researchers on Asians) and cE-Bs (Centre for Environment-Behaviour Studies), Faculty of Architecture, Planning \& Surveying, Universiti Teknologi MARA, Malaysia.

DOI: https://doi.org/10.21834/ebpj.v6iSI6.3036 
the performance of high school B40 students' English language proficiency based on The Common European Framework of Reference for Languages (CEFR) evaluation criteria using game-based intervention (GBI) in education. This has traditionally been the underrepresented group in the literature.

\subsection{Problem Statement}

Requirement's collection and analysis in English education is a fundamental process in various learning modules across secondary education. It is integral to the success of any software project whether it is a case study at the school level or whether it is a small or large project in industry. In particular, the application of game-based learning (GBL) intervention to teach was proposed. This study focuses on game-based intervention (GBI) in education as a pedagogical approach that involves the implementation of learning activities using one selected game. The purpose of this study is to examine if a game-based learning intervention can improve English language proficiency of students from the low-income group categorised as B40 in the Klang Valley. The codes refer to household income groups, with B40 representing the bottom $40 \%$ of income earners in Malaysia (Mahdzan, Zainudin, Sukor, Zainir, \& Ahmad, 2019). This is because a study by Babikkoi (2014) found a significant relationship between the socio-economic statuses of parents with learners' strategies to learning English. Besides, it was also confirmed in the study by Osonwa, Adejobi, lyam, \& Osonwa, (2013) that there was a relationship between parents' socio-economic status and academic performance of secondary school students. From the review, the researchers found that many of the game-based intervention (GBI) evaluations reported in the literature are generally weak with no emphasis on whether the learner has learned anything from the game (Connolly, Stansfield and Hainey, 2007). Thus, without strong empirical evidence supporting the use of games in learning, game-based intervention (GBI) can always be dismissed as unsubstantiated optimism.

Simultaneously, there is an increase in policies that encourage and support teachers to adopt interdisciplinary tools like games in Malaysia (Malaysia Education Blueprint, 2015). However, despite gaining attention and the increasing popularity of gamification in the education field, there are critiques of insufficient and inconclusive empirical evidence to support its effectiveness (Dichev \& Dicheva, 2017). This is due to a less rigorous designed research to study the potential of gamification in education (Nordby, Øygardslia, Sverdrup, Sverdrup, 2016). This controversy is also reflected in some empirical studies of gamification in education, which show that its effect on motivation or participation is lower than the expectations created by the hype (Francis, Russell-Bennett, Zainuddin, Kuhn, 2018). The empirical research should thereby not just be fixated on the pros of gamified learning, but also be open to the cons and the conditions when gamification for learning should be avoided. This clear position on the benefits of games for learning contrasts with the practice of game use in the classroom. Findings such as these are not surprising given the marginal progress made in the field to test and frame learners' performance in GBL (Foster \& Shah, 2020). Trends from policies, survey reports, and the societal attitude to digital games suggest it is the right time for researchers to respond to the interest in understanding how using games for learning can become a part of teacher's repertoire of professional skills and competencies (Fishman et al., 2014; National Research Council, 2011; US Department of Education, 2017).

Based on the literature, this study addresses one identified research problem: that is the lack of empirical evidence to support the use of game-based intervention (GBI) related to performance in the contexts of learning English (B40). This research problem addressed the use of game-based intervention to teach English. The identified research problem has been formulated to provide a methodical approach to address the primary contribution to knowledge. In addition, technological innovations have made online learning more easily executed. Simultaneously, there is an increase in policies that encourages and supports teachers to adopt interdisciplinary tools like games in Malaysia (Malaysia Education Blueprint, 2015). However, despite gaining attention and the increasing popularity of gamification in the education field, there are critiques of insufficient and inconclusive empirical evidence to support its effectiveness (Dichev \& Dicheva, 2017). Findings such as these are not surprising given the marginal progress made in the field to test and frame learners' performance in GBI (Foster \& Shah, 2020). To sum up, this study used game-based intervention to assist teaching and learning of English language using a sample of high school students from B40 socio economic groups in the Klang Valley. The primary contribution to knowledge was the production of empirical evidence in the game-based intervention (GBI) in the English education field. The findings will assist education industry in sparking the interest for improving language literacy achievement among high school students using technological kits as a pragmatic learning approach.

\subsection{The Common European Framework of Reference for Languages (CEFR)}

The Common European Framework of Reference for Languages (CEFR) is an international standard for describing one's level of proficiency in English language. It describes language ability on a six-point scale (Table 1), from A1 for beginners, up to $\mathrm{C} 2$ for those who have mastered the language. CEFR offers not only teachers and test developers, but also parents, learners, and employers with a clearer standard benchmark of the level of proficiency one possesses. Also, it dictates a more comprehensible description of language proficiency as it can be interpreted in the same way by users everywhere. As an example, a learner assessed as at level B1 in CEFR in one school should in principle be able to perform basically the same as a B1 learner in another school or even in another country, making this framework being acknowledged as a suitable and credible benchmark for English standards in Malaysia, after being researched for more than 30 years. CEFR is recognised in more than 40 countries and is now being used in countries far beyond Europe, including Mexico, Canada, Japan, China and Vietnam. To date, many international high-stakes tests such as IELTS, TOEFL, and TOEIC are aligned to CEFR signaling how CEFR has now being featured prominently in the reform of English language education in Malaysia, as laid out in English Language Education Reform in Malaysia: The Roadmap (2015-2025) also known as English Roadmap. 
Table 1: The Common European Framework of Reference for Languages (CEFR) level

LEVEL TEST SCORE EC LEVEL

VOCAB SIZE

CEFR LEVEL

\begin{tabular}{|c|c|c|c|}
\hline \multirow{2}{*}{\multicolumn{2}{|c|}{ Level 1: Pre-Beginner }} & \\
\hline & & 700 & A1 \\
\hline $11-25$ & Level 2: Low Beginner & $700-1.400$ & A1 \\
\hline $26-40$ & Level 3: Low Intermediate & $1.400-2.200$ & A2 \\
\hline $41-55$ & Level 4: Intermediate & $2.200-3.000$ & B1 \\
\hline $56-70$ & Level 5: Low Advanced & $3.000-5.000$ & B2 \\
\hline $71-85$ & Level 6: Advanced & $5.000-8.000$ & C1 \\
\hline $86-100$ & Level 7: Upper Advanced & $8.000+$ & $\mathrm{C} 2$ \\
\hline
\end{tabular}

(Source:) Cambridge University Press \& Assessment, (2021). International language standards.

\subsection{Game-based intervention}

One open-access game application was created by gamers and educators focusing on helping people in learning English in more fun and creative ways, this game is targeted at the youths and communities around the world from different socio-economic backgrounds. The expanding acceptability of digital learning platforms, their highly interactive nature among peer learners, affordability, and, most crucially, the knowledge acquisition method that is superior to traditional teaching, were the driving forces behind the creation. The designed game has been kept simple and free of complexity to serve in constrained settings and entertain learners with minimal digital expertise. After determining the need, the application was created with the goal of providing an engaging learning environment with blended learning features that combines gaming and learning.

This game was developed with a mission to serve as a platform that provides everyone with access to effective education. To improve engaging educational opportunities for learners, the application combines learning-mechanics and game mechanics context with social elements, artificial intelligence, and data. This interactive free game increases learners' acquisition of English effectively by utilising the 30,000 teaching materials that have been included in the application and is practical in application of everyday English vocabulary, grammar, phrasal verbs, and much more.

\subsection{Research Methodologies}

\subsection{Main Research Objectives}

The primary objective of this research is to use the game-based intervention approach to attempt to understand its contributions to the level of English Language proficiency among secondary school students from different B40 economic status backgrounds. The game was tested, and this contributes to one of the main problems of game-based intervention (GBI), which is the lack of empirical evidence. It will aid in addressing one of the important future research directions of game-based intervention (GBI) highlighted by Whitton (2007), namely more rigorous and robust quantitative comparative experimental designs using a control group that is taught in a traditional format.

\subsection{Research Design}

The repeated measures design is where the groups participate in the same conditions ensuring that the participants will have identical characteristics. This design is however vulnerable to an order effect and participants can either experience benefit from practice or fatigue leading to confounding. Therefore, the experimental design selected for all the game-based intervention (GBI) in English education experiments was done using correlation analysis to see the relationship between time spend on game-based intervention learning and the student's English syllabus performance. To do this, letters of invitation to participate in this study were sent to selected schools in Klang Valley. Schools/English Teachers administered the registration and the application of the students. Teachers also assisted the volunteer students to download the application. The study involved a total of 104 participants, with students coming from different forms i.e., Form 1 - Form 5 B40 groups. Statistical analysis techniques began with the process to clean the data from duplicates in the Learnalytics (LA) accounts and respondents with incomplete data. After doing the preliminary checking, the data was found to be either non-normal or containing outlier hence the analysis was done using Spearman and Kendall correlation analysis where the researchers calculated the correlation result (significance is based on alpha $=0.1$ ) (May and Looney, 2020; Cohen, 1988).

\subsection{Results}

\subsection{Participants}

The sample consisted of 104 high school students in Klang Valley from family with B40 economic background. In terms of gender distribution, there was a split between female and male ( $42 \%$ females vs. $58 \%$ males). In terms of age, all respondents were between 13 to 17 years' old. Thus, the researchers believe that in this study, age and gender are presented in the sample in ways that would provide the necessary variation to study game-based intervention-related variables. Based on the data from the analytic study, on average, the students spent 4.7 hours learning English on the application within the study period. 


\subsection{Correlation}

Results in Table 2 indicates that out of 104 students tested, more than $50 \%$ (54) shows a significant result in improvement with moderatestring correlation and statically significant based on alpha $=0.1$. For $C E F R$ score level $A 1$ (Beginner) $R=0.3191, P=0.0897$ (Kendall) and $\mathrm{R}=0.4051, \mathrm{P}=0.0966$ (Spearman), A2 (English Basic User (Elementary English)) $\mathrm{R}=0.1497, \mathrm{P}=0.2306$ (Kendall) and $\mathrm{R}=0.2341, \mathrm{P}=$ 0.1899 (Spearman) and B1 (English Independent User (Upper-Intermediate English)) $R=0.3879, P=0.0913$ (Kendall) and $R=0.5181, P$ $=0.0845$ (Spearman) (refer May and Looney, 2020; Cohen, 1988). However, results shows that there is no correlation between gamebased intervention and syllabus performance for students in the Pre-A (English Basic User (Pre-beginner)) and no conclusion can be made for students in the B2: English Independent User (Upper-Intermediate English) level as there are not enough data. To summarize, as Table 2 shows, the use of the game-based intervention platform does correlate with the syllabus improvement in some students. Thus, participants who have used the game-based intervention may have necessarily influenced their English learning performance.

Table 2: Correlations (Kendall and Spearman) between total duration on game-based intervention learning and syllabus improvement

\begin{tabular}{|c|c|c|c|c|c|}
\hline & \multicolumn{5}{|c|}{ Correlation (Syllabus Improvement vs Total duration (minutes)) N=104 } \\
\hline & Pre-A & A1 & A2 & B1 & B2 \\
\hline $\mathrm{N}$ & 47 & 9 & 33 & 12 & 3 \\
\hline Kendall & $\begin{array}{l}R=0.0077 \\
P=0.0641\end{array}$ & $\begin{array}{l}R=0.3191 \\
P=0.0897\end{array}$ & $\begin{array}{l}R=0.1497 \\
P=0.2306\end{array}$ & $\begin{array}{l}R=0.3879 \\
P=0.0913\end{array}$ & $\begin{array}{l}R=-0.3333 \\
P=1.0000\end{array}$ \\
\hline Spearman & $\begin{array}{l}R=0.0473 \\
P=0.0552\end{array}$ & $\begin{array}{l}R=0.4051 \\
P=0.0966\end{array}$ & $\begin{array}{l}R=0.2341 \\
P=0.1899\end{array}$ & $\begin{array}{l}R=0.5181 \\
P=0.0845\end{array}$ & $\begin{array}{c}R=-0.5 \\
P=0.6667\end{array}$ \\
\hline Interpretation & No correlation & $\begin{array}{c}\text { Moderate correlation and statistically } \\
\text { significant }\end{array}$ & \begin{tabular}{|l} 
Low negative correlation \\
and statistically significant
\end{tabular} & $\begin{array}{c}\text { Moderate - strong correlation and } \\
\text { statistically significant }\end{array}$ & $\begin{array}{l}\text { Not enough } \\
\text { sample }\end{array}$ \\
\hline
\end{tabular}

\subsection{Discussion}

This study was aimed at assessing game-based intervention, implemented within an English learning environment in the context of B40 high school student's English education system. This was done to answer the research question, "To what extent does the use of gamebased intervention (GBI) relate to performance in high school students English learning contexts (B40)?”. The results indicated that gamebased intervention improves learning performance in English education.

The understanding and interpretation of students employing the use of game-based learning for English education has given significantly better learning experiences to assist students learning. Therefore, through the perceived learners' impression and judgement, the game-based application has made a positive advancement on English learning dynamics. In other words, learners' exposure to the gamified learning platform has positively perceived the delivery of design and analysis of algorithmic education relative to those who are from traditional teaching type (Haruna et al. 2019). Considering these findings, it shows that Game-based learning has improved competency among high school B40 students in Klang Valley Education towards the study of English.From this observation the researchers can say that, self-study becomes more visible and deeper (Oyelere et al. 2018; Shyshkanova et al. 2017), thus helps recognize and annihilate the gap. However, due to a small study period and seemingly small number of participants, this study may not have a wellestablished observation and would require a comprehensive experiment for thorough implementation and instruction for higher education system.

\subsection{Conclusion}

Applications for Game-based intervention in this study were developed to motivate learners and give a boost to their English learning outcome in the context to high school students setting. in exploring the wider response, the researchers accrue from the experience towards the use of the applications for game-based intervention, the researchers can conclude that there is a strong desire among students to determine the need for digital learning and its integration into the school to support this type of learning. Making use of technology in teaching is not an end as such. "How and what students learn with their mobile devices largely depends on how technology is integrated to support teaching and learning processes" (Parajuli, 2016). There should be proper preparation from the department itself in terms of teaching practice, which encourages the use of mobile learning in addition to face-to-face learning, thereby embracing its definitive relationship with English learning performance. As a result of the study, it can be concluded that game-based learning applications have aided learners in their English learning. 


\subsection{Limitations \& Future Works}

Despite having positive results from the students, there are certain limitations in this study, which is hence, proposed to be addressed in the future work. First, the small participant size could undermine the generalizability of the findings. Additionally, this research was based on B40 Klang Valley higher education system where game-based learning is not a novice proposition, thus, the application may not be concluded in a global outreach. In addition, more robust framework is needed for game-based intervention learning practices within and outside of the classroom along with extensive assessment and learning methods. A culture of sharing of information and resources should be developed. Additionally, the researchers propose to test the application in contrast to the traditional teaching method to evaluate the learning outcome of the program, for example testing the application with two separate group of students and reviewing the learning result.

\section{References}

Babikkoi, M. A. (2014). Implications of Parents' Socio-Economic Status in the Choice of English Language Learning Strategies among Nigeria's Secondary School Students. English Language Teaching, 7(8), 139-147.

Connolly, T.M., Stansfield, M.H. and Hainey, T. (2009). Towards the Development of a Games-based Learning Evaluation Framework, In Games-based Learning Advancement for Multisensory Human Computer Interfaces: Techniques and Effective Practices (Eds: T.M. Connolly, M.H. Stansfield and E. Boyle). Idea-Group Publishing: Hershey. ISBN: 978-1-60566-360-9.

Cohen, J. (1988). Statistical power analysis for the behavioral sciences (2nd ed.). New Jersey: Lawrence Erlbaum.

Dichev, C., \& Dicheva, D. (2017). Gamifying education: what is known, what is believed and what remains uncertain: a critical review. International journal of educational technology in higher education, 14(1), 1-36.

Foster, A., \& Shah, M. (2020). Principles for Advancing Game-Based Learning in Teacher Education. Journal of Digital Learning in Teacher Education, 36(2), 84-95. Haruna, H., Zainuddin, Z., Mellecker, R. R., Chu, S. K. W., \& Hu, X. (2019). An iterative process for developing digital gamified-sexual health education for adolescent students in low-tech settings. Information and Learning Sciences, 120(11/12), 723-742.

Justine O May and Stephen W Looney (2020). Sample Size Charts for Spearman and Kendall Coefficients. J Biom Biostat 11. doi: 10.37421/jbmbs.2020.11.440 Mahdzan, N. S., Zainudin, R., Sukor, M. E. A., Zainir, F., \& Ahmad, W. M. W. (2019). Determinants of subjective financial well-being across three different household income groups in Malaysia. Social Indicators Research, 146(3), 699-726.

Ministry of Higher Education (2015). Malaysia Education Blueprint 2015-2025 (Higher Education).

Osonwa, O. K., Adejobi, A. O., Iyam, M. A., \& Osonwa, R. H. (2013). Economic status of parents, a determinant on academic performance of senior secondary schools students in Ibadan, Nigeria. Journal of Educational and Social Research, 3(1), 115-115.

Oyelere S, S., Suhonen J, Laine T, H. (2017). Integrating Parson's programming puzzles into a game-based mobile learning application. In proceedings of the 17th Koll Calling International Conference on Computing Education Research, (pp. 158-162). New York, NY: Association for Computing Machinery. https://doi.org/10.1145/3141880.3141882.

Oyelere, S. S., Suhonen, J., Wajiga, G. M., \& Sutinen, E. (2018). Design, development, and evaluation of a mobile learning application for computing education. Education and Information Technologies, 23(1), 67-495.

Parajuli, K. P. (2016). Mobile learning practice in higher education in Nepal. Open Praxis, 8(1), 41-54.

Plass, J. L., Mayer, R. E., \& Homer, B. D. (Eds.). (2020). Handbook of game-based learning. Mit Press. Retrieved April 1, 2021 from https://www.um.edu.my/docs/defaultsource/about-um_document/media-centre/um-magazine/4-

Shyshkanova, G., Zaytseva, T., \& Frydman, O. (2017). Mobile technologies make education a part of everyday life. Information and Learning Sciences, 118(11/12), 570582. 